\title{
On Elastic Ties: Distance and Intimacy in Social Relationships
}

\author{
Stacy Torres
}

University of California, San Francisco

Abstract: Drawing on five years of ethnographic fieldwork among older adults in a New York City neighborhood, I present empirical data that complement survey approaches to social isolation and push our understanding of social ties beyond weak and strong by analyzing relationships that defy binary classification. Usual survey items would describe these participants as isolated and without social support. When questioned, they minimize neighborhood relationships outside of close friends and family. But ethnographic observations of their social interactions with neighbors reveal the presence of "elastic ties." By elastic ties, I mean nonstrong, nonweak relations between people who spend hours each day and share intimate details of their lives with those whom they do not consider "confidants." Nonetheless, they provide each other with the support and practical assistance typically seen in strong-tie relationships. These findings show how people's accounts may not accurately reflect the character and structure of their social ties. Furthermore, they demonstrate how a single social tie can vary between strong and weak depending on the social situation. Many social ties fall outside weak and strong; they are elastic in allowing elders (and other marginal groups) to connect and secure informal support while maintaining their distance and preserving their autonomy.

Keywords: aging; life course; community; ethnography; social ties; public space

Citation: Torres, Stacy. 2019. "On Elastic Ties: Distance and Intimacy in Social Relationships." Sociological Science 6: 235263.

Received: November 15, 2018

Accepted: February 18, 2019

Published: April 9, 2019

Editor(s): Jesper Sørensen, Mario Small

DOI: $10.15195 / \mathrm{v} 6 . \mathrm{a} 10$

Copyright: (C) 2019 The Author(s). This open-access article has been published under a Creative Commons Attribution License, which allows unrestricted use, distribution and reproduction, in any form, as long as the original author and source have been credited. (0)(1)
T Pete's delicatessen, ${ }^{1}$ regulars like Sylvia and Eugene sipped coffee and engaged in animated discussion most days. Eugene was an 87-year-old white man, originally from Texas, politically conservative, and never married. He had lived in New York City for 50 years, the last 37 in the same rent-stabilized apartment around the corner. Sylvia was an 83-year-old, liberal, Jewish woman from Brooklyn, widowed for 17 years. She lived in the neighborhood 40 years but joked, "I needed a passport when I came."

On this chilly evening, Eugene sat with his back against the ATM.

Sylvia teased him, saying, "I notice you're leaning against the money machine. Is it keeping you warm?"

Eugene laughed. "Yeah, that's how I'm going to get the money," he said, wiggling his fingers as if to coax bills from the machine. More likely, Eugene sat at this angle, leg stretched, because of last year's hip operation.

Eugene and Sylvia liked to laugh together and saw each other at Pete's most evenings and nearly every morning.

"The boss has been speaking to me lately," Sylvia said, referring to the middleaged Korean storeowner. "He asked me about you," she told Eugene. "He said, 'How do you know him?' I explained, 'Well, he's a friend and a neighbor."'

Eugene added playfully, "We met in prison." The three of us cracked up. Eugene squeaked with laughter and could barely finish a sentence, Sylvia giggled so hard she grabbed my arm to steady herself, and I teared up. 
When the laughter faded, Sylvia extended the joke, "We met at Rikers."

With a smile, Eugene said, "It was co-ed back then."

"Yeah, we were the last two at Alcatraz," Sylvia said.

As I detail below, the relationship Eugene and Sylvia had formed over 10 years of face-to-face interactions suggested a deeper bond than acquaintanceship or "weak ties" (Granovetter 1973). Yet, they did not name each other when I asked them, using the General Social Survey measure, to list those with whom they had discussed "important matters" during the previous six months. Their interactions fulfill many criteria for "strong ties," but their accounts of this relationship suggest their connection would remain invisible in many network surveys.

Sociologists' interest in social integration dates to the discipline's founding (e.g., Durkheim [1897] 1951; Simmel [1908] 1971, [1910] 1971); and the extent to which isolation has waxed and waned has fueled perennial debate (e.g., Bellah et al. [1985] 1996; Putnam 2000). Social media have inspired twenty-first-century handwringing over the potential for isolation and optimism about new forms of connection (McPherson, Smith-Lovin, and Brashears 2006; Paik and Sanchagrin 2013; Rainie and Wellman 2012). Concern stems in part from negative outcomes related to a dearth of social ties. Lacking ties can increase stress and poor mental and physical health. Robust networks provide a sense of belonging, social support, and access to resources, such as cash and other practical assistance (Loe 2011; Small 2009). "Social capital" also acts as a public good, and benefits can reach the larger community (Putnam 2000).

Beyond quantifying and mapping ties, network analysts have also developed definitions of tie strength. Granovetter (1973) writes that four features characterize the strength of ties: intimacy (mutual confiding), time spent together, reciprocal services, and emotional intensity. Today, this definition remains relevant, and sociologists have reached some consensus that Granovetter's criteria capture important close relations. Whereas strong ties fulfill several criteria, weak ties help move information and resources between networks that have little or no contact. Despite advances in network analysis, relationship categories have undergone less interrogation. Questions remain about the dimensions of supportive relationships, the stability of relationship categories, and what happens during interaction between network members. In this article, I advance an alternative approach to classifying those relationships that possess qualities of "closeness" but defy classification as either weak or strong.

To better understand the social ties older adults forge as they grapple with aging and neighborhood change, I conducted a five-year ethnographic study (2009 to 2014) in New York City in which I followed participants aged 60 years and older as they coped with the closing of neighborhood establishments; the loss of neighbors, friends, and family; health setbacks; depression; financial struggles; and other challenges. Their relations possessed intimacy and distance. Questioning participants about their associations with each other and observing them in multiple sites revealed the presence of what I call "elastic ties." Like a rubber band, ties stretched to accommodate participants' needs for autonomy and connection. Strength came from their elasticity, allowing closeness with distance and the freedom to pull back. Associations that appeared superficial or fleeting showed strength when mobilized 
during crisis and everyday challenges. Yet people who appeared close by the criteria for strong ties expressed ambivalence about labels such as "friend" and implemented distancing strategies, including not learning or remembering each other's names. Depending on context, elements of closeness and distance could coexist in a single interaction or tie; I call these nonstrong, nonweak ties elastic to highlight these temporal and situational features.

I also show that old age provides an analytical opportunity to examine this fluid relationship that rises in salience during late life and may have implications for other groups facing similar conditions. Elastic ties develop in response to opportunities and constraints associated with the transition to retirement, the changing relationship to neighborhood and to time, and the loss of spouses, partners, friends, and physical ability (see Stueve and Gerson 1977). Features observed in other relationships, which I will discuss, coalesce under these conditions to form a type of elastic relationship that allows older urban residents to secure informal support while preserving autonomy. Given the needs of an aging population, we must understand how elastic ties complement other kin and nonkin support. These findings represent an important step towards theorizing network transformation later in life and build on prior scholarship that examines ties outside of weak and strong. Desmond (2012) described a related category of tie: a "disposable" tie characterized by high yet fleeting support. In contrast, elastic ties also offer strong support, but their distance allows participants to sustain assistance. They subvert conventional wisdom on friendship, acquaintanceship, and the strength of ties and enrich our understanding of how people build support networks across the life course.

After describing my methods and data, I juxtapose the observed strength of elastic ties with the simultaneous social distancing that my participants demonstrated in their interactions and assessments of these relationships. I then outline the obligations of strong ties that may dissuade people from acknowledging more friendships, thereby reducing the burden and expense of closer relationships, and discuss elastic ties as they relate to participants' motivations for downplaying intimacy and maintaining distance. I close by specifying how my observational study of elastic ties complicates conventional understandings of network relations. I conclude this discussion with a fuller conceptualization of elastic ties and articulate the relevance of this ethnographic approach for the structural perspective on social-network analysis.

\section{Social Connection in Old Age}

Prior research has shown that higher rates of living alone, physical illness, and depression increase older adults' risk of social isolation. Social ties prove consequential for solo dwellers who have weaker kin ties due to physical distance or have outlived close friends and family. The prevalence of isolation among the old remains unclear. Although retirement and bereavement may diminish connections, and deteriorating health may limit activities, some research has found that older people face less loneliness and isolation than previous studies suggested (Hooyman and Kiyak 2008; Schnittker 2007). Retirement also gives people more time to socialize, and scholars 
have found that social interaction and volunteering increase with age (Cornwell, Laumann, and Schumm 2008; York Cornwell and Waite 2009). Older people may also experience changes in relationship expectations that help them cope with loss and gain greater satisfaction with their networks. Socioemotional selectivity theory posits that elders pare networks to maximize positive emotions from fewer ties, whereas younger people seek information and professional advancement from more contacts (Carstensen 1992; Schnittker 2007). Prior studies have shown that larger networks contain a higher percentage of supportive ties (Wellman and Gulia 1999). Older people's smaller networks may affect later wellbeing.

Isolation research concentrates on older people because they often live alone. The number of one-person households and elders living alone has climbed throughout the late-twentieth and early-twenty-first centuries (Klinenberg 2002, 2012), often due to partner loss but also the choice to live alone (Townsend 1957). Urban areas tend to have higher rates of solo dwellers, which challenge authorities in places such as New York City to identify those most vulnerable to isolation (Gusmano and Rodwin 2006). Nevertheless, many scholars of aging have argued that disciplines such as gerontology have focused too much attention on problems of old age, such as isolation (Wellin 2010). They advocate increased study of the support that older people provide to other network members in addition to receiving care (Townsend 1957; Victor, Scambler, and Bond 2009).

Despite arguments over the declining importance of the neighborhood for creating networks (Plickert, Côté, and Wellman 2007; Rainie and Wellman 2012; but, see Sampson 2012), the neighborhood can increase as a source of social ties for older people, especially for those with limited physical mobility and who can no longer drive (Abramson 2015). Fischer (1982:184) found that older people's social worlds "tended to be spatially circumscribed," leaving few options other than within their communities to form ties outside family. Street-level geography may matter more in urban areas, where people rely on public transportation and walk to local shops and parks (Ben Noon and Ayalon 2018; Cagney et al. 2013; Kugelmass [1986] 1996; Myerhoff 1978; Oldenburg 1989 [1999]). Hochschild (1973) observes that workingclass elders depend more on the neighborhood for relationships, which can buffer the loss of work-based ties (see also Duneier 1992; Furman 1997; Victor et al. 2009). But although the neighborhood's importance may grow for elders, network studies have devoted less attention to the category of neighbors than core relations (Morgan 2009; Townsend 1957; Victor et al. 2009; Wellman and Wortley 1990). Thus, our understanding of their significance remains underdeveloped compared with knowledge of elders' closest and strongest ties.

\section{Prior Approaches to Studying Social Ties}

\section{Network Measures of Social Connectedness}

Surveys have offered an important cross-sectional portrait of people's social networks. For example, the General Social Science Survey (GSS) social-network module provides valuable data on Americans' core discussion networks (Bearman and Parigi 2004). The central question reads: "From time to time, most people discuss 
important matters with other people. Looking back over the last six months, who are the people with whom you discussed matters important to you? Just tell me their first names or initials" (Fischer 2009). More recent work (McPherson et al. 2006) on the "important-matters" question sparked new discussion in the debate over isolation. Their findings prompted concern over the uptick in people with no one to talk to and skepticism. Fischer (2009:657) claims that such dramatic social change without explanation was an "artifact," perhaps the result of interviewee fatigue or difficulty interpreting the question. Additional critiques attributed the 2004 GSS isolation findings to measurement error at the interviewer level (Paik and Sanchagrin 2013).

Previous studies have attempted to understand what "important matters" captures (Bailey and Marsden 1999). Scholars agree that this name generator best gauges respondents' strongest ties, including kin networks and relations such as best friends and romantic partners (Bearman and Parigi 2004; Marsden 1987, 1993; but see Small 2013). Such emphasis has consequences for measuring the strength of less central ties, such as neighbors and acquaintances, which I argue matter more for older people with fewer core ties (Cagney et al. 2013; Suanet, van Tilburg, and van Groenou 2013). As my fieldwork uncovered, people discussed personal issues, such as medical conditions, family problems, and money concerns, at length with people for whom they could not provide a full name and in some cases not even a first name. If a person does not know someone's initials and feels uncertain about how to categorize them, they may not mention them on a survey. Furthermore, people might not identify public places as appropriate venues for discussing important matters and thus might not volunteer ties there as close contacts. This oversight could result from not recalling interactions considered superficial or reluctance to name them as confidants in absence of family or friends.

Eliciting names to create network rosters takes time, and longitudinal network analysis remains rare (McPherson, Smith-Lovin, and Cook 2001). Some surveys, such as the National Social Life, Health, and Aging Project (NSHAP), have pieced together more complete respondent networks through extensive probing. Yet, the main surveys of older adults rely on the important-matters question to generate respondents' networks (Longitudinal Aging Study Amsterdam 2017; National Social Life, Health, and Aging Project 2011; Survey of Health, Ageing and Retirement in Europe 2015). For example, although the Survey of Health, Ageing and Retirement in Europe (SHARE) (2015:16) offers 27 categories from which respondents can list network members with whom they discussed important things, follow-up questions stress people who are "important to you" as the key characteristic of the relationship. NSHAP (2011:6) uses a similar important-things question, with a list of relationship options, followed by probes about frequency and method of contact between network members and family and friend support. Thus, the network hinges on the identification of close, defined relationships. Meanwhile, the Longitudinal Aging Study Amsterdam (2017) uses repeated probes that stress contacts with whom the respondent is "in touch regularly" and finds "important," potentially missing anyone outside a recognizable relationship significant to the interviewee. 
These surveys also collect minimal information about respondents' neighborhoods and time spent in public spaces. NSHAP and SHARE broadly define the neighborhood as the area within a 20-minute walk, or a kilometer to a mile, around the home. All three surveys gauge respondents' agreement with statements about neighborhood safety and cleanliness, feelings of belonging, availability of help, and perceptions that the area is close knit or people can be trusted.

Although improved design, increased interviewer training, early placement of egocentric name generators, and additional follow-up questions may mitigate some issues (Paik and Sanchagrin 2013), I argue that the best surveys still miss in situ action and offer responses divorced from context. Observational methods can help network analysts uncover social relations that fall outside predefined survey categories by providing a window into a form of intimacy that traditional name generators are not designed to pick up (Victor et al. 2009). Although useful in revealing close ties, name generators obscure the finer qualities of indeterminate relationships that are easier to overlook given the closed-ended nature of many survey questions. The intimate qualities of elastic ties challenge core definitions and assumptions of what makes a relationship strong, raising the question, what is closeness?

\section{Theorizing the Space Outside Strong and Weak Ties}

Despite attention strong and weak ties have received in network research, some scholars have examined ties outside these designations and take the contradictions of relationships as a starting point of analysis. Simmel used the stranger to illuminate "the union of closeness and remoteness involved in every human relationship" ([1908] 1971:143). The stranger's simultaneous insider-outsider position speaks to the desire to participate in relationships and stand outside them. His ability to straddle the line of belonging grants the stranger a freedom that others in dense networks lack. In Simmel's words, the stranger illustrates how “... factors of repulsion and distance work to create a form of being together, a form of union based on interaction" (Simmel [1908] 1971:144). And in the present day, contact with strangers in urban areas occurs more frequently than in the small-village context Simmel describes.

Work in this vein has focused on intimacy between people with similar vulnerabilities. As the concept of strong and weak ties draws from middle-class experiences, such as white-collar employment seeking (Desmond 2012), ties outside this binary tend to serve disadvantaged people who lack access to resources. For example, Liebow (1967) observed that many African American streetcorner men elevated what others may consider passing acquaintances to close friendships with men for whom they had little knowledge of personal history, present circumstances, or sometimes a last name. Modeling friendship networks on kin relationships resulted in "going for brothers," in which two men presented themselves publicly as brothers, thus heightening the obligations and loyalties of friendship. Despite accelerated intimacy, Liebow discovered the instability of personal networks, writing, "Attitudes toward friends and friendships are thus always shifting, frequently ambivalent, and sometimes contradictory" (1967:117). Desmond's (2012) study of 
survival strategies among evicted tenants in high-poverty neighborhoods echoes Liebow's findings. They relied more on acquaintances than relatives for food, child care, and shelter. However, despite high support, ties proved fleeting and unstable; Desmond calls them "disposable ties."

Others have argued the importance of "third places," where people form ties through fleeting or regular interaction (see Anderson 2004; Brown-Saracino 2011; Gieryn 2000; Lofland 1973; Oldenburg 1989 [1999]; Torres 2018). Lofland (1998) defines the social territories of neighborhood, workplace, and acquaintance networks as the "parochial realm" and argues that despite common knowledge of people's attachment to these spaces, empirical observations of people in public remains limited. Morrill and Snow (2005) argue that interactions between strangers and "nonintimates" in public places, such as "familiar strangers" (Milgram 1977) like regular train commuters and bar customers, gain significance as families and friendship networks shrink. Small (2009) found that mothers' ties in day care centers provided surprising support, especially for low-income, urban mothers. Centers afforded space and opportunity to build trust through repeated interactions so that ties transcended acquaintanceship and mothers became "compartmental intimates." Their closeness remained limited to child-centered activities and conversations in the centers. Small's (2017) network study of first-year graduate students also found spaces created opportunities to confide in those with whom they did not have a close relationship.

Studying ties forged through interactions of this kind also has implications for understanding how people manage significant social transitions, such as divorce, job loss, or a move. Further, observing people's actions over time moves debate about network measures and methods beyond fatigue and recall problems to consider the deeper limitations of confidant as a relationship category. Small writes, "People are far more willing to confide personal matters to those they are not close to than they are inclined to believe about themselves, than network theory would propose, and than social science is likely to uncover without expanding the way it studies networks" (2017:6). And yet, although these conceptualizations have advanced sociological understandings of how people accelerate intimacy in seemingly distant relationships, none have theorized the inverse and focused on the active distancing that characterizes elastic ties.

\section{Methods and Setting}

La Marjolaine Patisserie, the study's initial site, occupied a storefront leased by a low-equity co-op ${ }^{2}$ for 11 years. Since 1962, a bakery operated in the same retail space. La Marjolaine sat nestled among three main residential swathes: the co-op, public housing projects, and a large rental complex. A number of these buildings' tenants patronized the bakery. Many longtime, lower- to middle-income residents had remained in a neighborhood now home to high-end restaurants and million-dollar condominiums because of rental protections afforded to them in the projects and co-op or through rent control and stabilization programs in the rental buildings. They "aged in place" and lived independently in buildings classified as naturally occurring retirement communities (NORCs), which federal law defines as 
"a community with a concentrated population of older individuals" (Niesz 2007). New York City has approximately 27 NORCs (Interboro Partners 2010).

Although I took field notes ${ }^{3}$ at this site for six months, my observations date to 2004, when I first came into La Marjolaine as a customer. I entered the field during a project for an ethnographic research methods course during my doctoral studies. Prior acquaintanceship with key figures helped me meet other bakery regulars. This group of roughly 47 women and men aged 60 years and older skewed female, Puerto Rican, Jewish, ethnic white (Italian, Greek, and Irish descent), and low to middle income. I observed the bakery during mornings, afternoons, and evenings an average of four to five times per week for a minimum of two hours. I recorded my observations until the bakery closed after the owner failed to renew the lease because of a rent increase, upon which my study expanded as former customers decamped elsewhere. I ended up primarily in two sites for an additional 4.5 years-McDonald's and Pete's Delicatessen-where many former bakery customers gathered. I observed a greater number of people (approximately 136) than the group of regulars with whom I spent the most time. I also visited participants in their homes, hospitals, and nursing homes; attended wakes; and accompanied them to other neighborhood places. To supplement observations, I conducted 25 interviews with people recruited from the baker. These interviews asked about biographical information, residential history, experiences of the bakery and afterwards, relationships, and daily routines.

I took handwritten field notes at the sites and afterwards. After writing detailed notes of the day's observations and conversations, I added brief analytic notes and memos, which helped later to uncover patterns, spark additional questions, and connect my data to prior scholarship. My analysis consisted of manually reviewing field notes and interview transcripts for related themes and emerging patterns, coding for relevant concepts and categories generated from the literature and my data.

Only after years of ethnographic fieldwork did I discover the discrepancy between people's accounts of their relationships and my observations of these ties. When I asked my interviewees the important-matters question, replicated from York Cornwell and Waite (2009), and more directly discussed with participants their relationships during participant observation, I found that people who appeared close rarely reported affective feelings, applied friendship labels, or named each other as confidants or conversation partners. The discrepancies revealed between my participants' accounts and actions stand as a compelling "warrant" (Katz 1997) for using observational methods to analyze the kinds of social relationships discussed below. Ethnography can serve as a powerful tool for uncovering and explaining discrepancies between what people say and what they do (see Desmond 2012; Goffman 2009; Jerolmack and Khan 2014; Khan and Jerolmack 2013; LaPiere 1934; Liebow 1967).

\section{Elastic Ties}

Though participants typically did not visit each other's homes or know each other's families, friends, and sometimes not even first names, elastic ties provided social 
support that helped them organize daily life and feel socially involved. By elastic ties, I mean nonstrong, nonweak relations between people who do not recognize each other as confidants but who nonetheless provide each other with the support and practical assistance typically seen in strong-tie relationships. Thinking of ties as elastic rather than fixed as weak or strong better reflects the complex, shifting relationships people forged during informal gatherings with no explicit agenda other than spending time in public (see Feld 1981). Like a rubber band, elastic ties stretched to accommodate the fluidity and spontaneity of social relations. The freedom to occupy "in-between" positions indefinitely allowed people to reach out as much as they desired or could, thereby keeping their options open as they balanced autonomy with commitment. Distancing served a protective function. Though elastic ties allow flexibility, if stretched too far, the bond, like a rubber band, can snap. Their more fragile sense of obligation can leave people stranded in a crisis if demands strain the tie.

In the following three subsections, I present data that outline the key components that form the backbone of elastic ties. The first subsection examines how the elastic ties that I studied often fulfilled the requirements of strong ties: intimacy (mutual confiding), time spent together, reciprocal services, and emotional intensity. The second subsection examines situations in which the same relations fell short of these criteria as participants maintained distance. In the third subsection, I present evidence that shows how the burden and expense of close relations lead people to avoid claiming greater intimacy and insert distance into their interactions.

\section{Establishing Closeness}

How did participants establish closeness with each other, and what did this form of intimacy look like? The presentation of data below demonstrates the ways that elastic ties often fulfilled the requirements of strong ties: intimacy (mutual confiding), time spent together, reciprocal services, and emotional intensity.

Confiding occurred on two levels, about past and present. People shared personal things about life events in childhood and the more recent past. One night at Pete's, during a discussion about crime and neighborhood safety, an 84-year-old woman named Phyllis announced that as a teenager, "I was raped." On another occasion at the deli, she described in graphic detail how her older brother died accidentally in World War II under friendly fire. Other discussions of personal histories included fond reminiscences and strained memories of family relationships and the loss of family and friends. Several times, Eugene spoke with great emotion about losing his mother at nine years old to tuberculosis. Likewise, Sylvia often shared stories about deceased relatives, including her siblings, husband, and most recently, a middle-aged niece. Sharing also happened about present concerns. Given most participants' advanced age, current worries involved health problems and their financial costs. During one discussion on these topics, Judy, 60 years old, revealed her breast cancer diagnosis at 18 years old and follow-up treatment, and Phyllis spoke with regret about her diabetes, claiming, "It was my fault. I ate too much sugar." Sylvia discussed her heart attack and a brain hemorrhage that still affects her memory and hearing. Lucy spoke candidly about ongoing treatment 
for chronic arthritis and the high out-of-pocket costs. Other issues that people discussed included complicated relationships with family members and everyday challenges, such as managing finances and shopping errands.

The following vignette illustrates the extent of people's confiding. One evening, Eugene shuffled into Pete's. "I have a story to tell you," he promised Lucy, Sylvia, and me, before heading to pay for his coffee. We continued chatting about Lucy's arthritis woes, never expecting the bombshell Eugene planned to drop. "As I said, I've got a story for you. I just got back from the VA [Veterans Affairs hospital]. I had a heart attack," Eugene said. His calm delivery heightened the dramatic effect. He waited for our reactions. Lucy nearly stood up from her seat across from Eugene as she exclaimed, "You what?" As her booming voice reached higher octaves, I almost feared she would bring on a second heart attack.

"My God," Sylvia said softly and touched her hand to her chest. Her lips pressed into serious line. "Are you all right?" she asked and patted Eugene's arm.

"Yes, I'm fine," Eugene said and explained that he had the attack yesterday while at the clinic for a checkup. He admitted feeling weak but seemed to enjoy the storytelling and smiled as he described watching the monitor show his heart beating during the angioplasty.

"I saw the whole thing," he said, mimicking the swooshing sound of his pounding heart on screen. When Eddie walked in 10 minutes later, he began the story anew and repeated details of his ordeal, such as the hospital losing his clothes and billfold and the two-hour delay while they searched for his things.

"Is that right?" Eddie murmured. He turned to me and chuckled, "We're seeing a ghost."

"I guess I'm indestructible," Eugene said.

Before leaving, Sylvia pulled Eugene's face toward hers and kissed his cheek. "I don't want to hear you're in the hospital again unless you're having a baby," she said with an affectionate laugh.

Granovetter (1973) identifies emotional intensity as a feature of tie strength, though he does not define it. Emotions offered an important lens into participants' investment in each other. The interactions I observed, such as the vignette described above, contained intense emotions, including concern, empathy, frustration, anger, distrust, and camaraderie. The presence of positive and negative emotions betrayed a deeper involvement between people who often claimed only a passing connection. My participants' attachment to each other also surfaced after their primary meeting spot, the bakery, closed. Some people expressed missing patrons they had seen every day for years. Many regularly reported their sightings of former customers, even those they disliked, revealing a form of caretaking among these difficult-tocapture relations. If they did not care about someone, they would not monitor their whereabouts with such vigilance.

Study participants spent much time together, unsurprising because older, retired people have more free time and often struggle to fill it. Two participants expounded their difficulties managing excess time. Lucy, a retired secretary in her late 70s known for her bright-red glasses and love of celebrity gossip, mentioned her boredom whenever Eugene discussed his writing projects. She envied his busyness as a working writer and never seemed to grow bored or lonely, though he lived alone. 
"He's lucky. Not everyone has that. I sure don't," she said. Sylvia, too, admitted needing escape from boredom and stress. Lotto helped. "I find it very entertaining," she said of her favorite scratch-off ticket. Because of advanced age, participants faced another paradox of time: They had less to waste and had to use it wisely.

The bakery's loose supervision allowed people to spend much time in the store together. The majority came almost every day, and many came more than once per day. Though no subsequent site provided the same arrangement as the bakery, people continued to see each other several times per week (four on average) and spend hours together. The experience of time changed depending on those present to socialize. Even with the most entertaining personalities, discussion eventually dragged. But each additional person eased the burden of keeping the conversation alive, and time seemed to pass faster. People-watching also served as an important source of entertainment.

Reciprocal services that people offered each other involved exchanging information, favors, and gifts, critical to people fighting to maintain their independence in old age. Most exchanges were never one sided, and instances when this occurred quickly produced strain (see Plickert et al. 2007 for more discussion of network reciprocity). Eugene's case illustrates how people participated in the giving and receiving ends of this information flow. He served as the group's resident nutritionist because of his published books on vitamins and provided a wealth of information to people for years, such as Carmen, a soft-spoken Puerto Rican woman in her late 70s. She went only to McDonald's and had not seen Eugene since the bakery closed two years before but asked me to thank him for educating her on vitamin D. Recipients also shared his information with others. Lucy followed Eugene's suggestions to treat her arthritis and passed information on macular degeneration to a friend. Eugene's knowledge also reached others whom he had not seen in years, such as Angelica, an undocumented immigrant from Spain who had worked at the bakery for three years. She received a breast cancer diagnosis, and I mentioned his suggestions to her when accompanying her to surgical consult appointments.

Eugene also received vital information. Sylvia informed him about Senior Citizen Rent Increase Exemption, a program that helps people age 62 years and older with fixed incomes avoid rent increases (City of New York 2016). She asked me to pick up an application for him from the state assemblyman's office six blocks away, too far to walk. Lucy said she would bring one the next day. Eugene and Sylvia lived in rent-stabilized apartments among neighbors who paid rents three and four times as high. Both faced unfair and confusing increases and harassment over the years. Eugene's most recent harassment resulted in a trip to housing court before the management company abruptly halted eviction proceedings. The information they exchanged aided their survival in a gentrifying city. Co-op residents faced less pressure because their rent rose and fell on the basis of income. Eugene also received important information from Eddie, a 79-year-old former construction worker, who also went to the Veterans Affairs hospital for medical care. For years, Eddie provided Eugene with information on navigating the hospital's clinic system, rotating doctors, and physical therapy office and tips on receiving prescriptions quickly. 
Beyond information sharing, participants also exchanged gifts, small loans, and other practical help, such as picking up something from the store. When Eugene had trouble paying his rent and other bills, Sylvia provided a few loans in $\$ 20$ to $\$ 40$ increments and confided to me that she did not expect him to pay her back. And for several years, a large group of bakery regulars took Eugene out for a birthday dinner. Many people treated each other to coffee and food at neighborhood eateries, sometimes because they knew someone had financial problems, such as Marjorie, who lived in the housing projects and often wore threadbare clothing and had no phone.

\section{Maintaining Distance}

People interleaved distance into social interactions more subtly than shunning others. Often, they infused moments of closeness with distance, seesawing back and forth in different situations. Participants created distance and downplayed their ties in four primary ways: not learning or remembering others' names, avoiding the label of friend, gossiping and badmouthing, and temporarily pulling back.

Many tended not to learn each other's names, and if they had, it was only months or years later. Most never learned last names. Early on, I assumed that closeness required knowing someone's name and that not knowing implied people had only a "nodding relationship" ("hi" and "bye"). My observations proved these assumptions wrong. I became aware that people who seemed close often did not know each other's first names during conversations I overheard about those who frequented the bakery. For instance, people referred to one bakery regular as Fran in her absence. I presumed closeness because of her frequent interaction with the other women, the time she spent with them, and the personal subjects they discussed, such as financial and medical problems along with happy childhood reminiscences. One evening, Lucy mentioned a woman who matched Fran's description, calling her Helen. I revealed my confusion, saying, "I thought her name was Fran." To my surprise, Lucy said, "So did we." Through gossip, I learned that not knowing people's first names was more common than I thought.

Martin's case illustrates how people connected with others at the bakery and the depth of connections that appeared superficial or fleeting. I had known him for years but had not seen him until 2.5 months into formal observations, when he returned to the bakery in the evenings. Martin's health had declined for months, but I noticed nothing different other than lowered energy. He shuffled rather than walked, staring down at his chest. I last saw Martin the night before Thanksgiving. He brought a watch band for Eugene as a small gift and sat laughing with him and Eddie. Days later, I learned Martin had died. I asked Eugene if he had heard. "Martin who?" he responded, looking perplexed. "I'm sorry, I don't know who that is." The next day, he confirmed that he had known Martin by face, not name, and expressed his sorrow, as typically occurred after a bakery regular died. No matter someone's advanced age or poor health, many felt surprised when a regular suddenly vanished.

Five months later, Eugene described the surprising depth of his attachment, though he had spoken with Martin mostly in the bakery. An affable man who got 
along with many people, Eugene did not often display deep emotion. We discussed people Eugene had met through the bakery. He mentioned that many had died. I asked for names, which produced this exchange:

Eugene: "What was his name? Was it Murray?"

Interviewer: "Oh, Martin?"

Eugene: "Yes, Martin. I was very fond of him. I took his death very hard."

Interviewer: "Oh, did you?"

Eugene: "Yeah."

Interviewer: "How come?"

Eugene: "Well, we used to chat a lot. He was into nutrition. And he was always saying, 'Have you heard of this?' 'Yeah, I've heard of that.' I'm sure I've told you this story. One day, I said, 'You know I've got to get a watch band. Mine is broken.' And one evening just before it was closing, he walked over and had a big box full of trinkets, of watch bands, a whole box full of things. He had made a trip especially over there. ... He was a wonderful man. It really brought tears to my eyes when I heard about it [his death]. And you told me. I didn't know... and I didn't know his name."

After the bakery closed, people used shorthand descriptions to identify former customers instead of first names: "the woman who took care of her mother," "the guy who dances," and "the man who scratches [lottery tickets]." Many blamed not knowing names on memory problems associated with aging. Initially, I also attributed oversights to forgetfulness. For instance, one woman with worsening dementia called everyone "Pepper" because she could not remember names. But I have become convinced that not keeping track of names can represent a deliberate strategy, though I cannot know whether people consciously employ this tactic. A woman in McDonald's discussed an extreme version of this strategy at the end of our first discussion, when I asked her name. She refused and explained her reasons for not revealing her name or learning anyone else's. “Oh, I don't give my name because then I have too many people calling me. Names don't matter, it's what's in here," she said, pointing to her chest. "What matters is the heart." I had never encountered such a refusal and felt guilty for asking. To show goodwill, I told her my name. She said, "Oh, I don't know names, just faces." During this interaction, I wondered if Gladys and Carmen, also present, knew her name. Carmen confirmed that she did not. "We don't usually sit with this woman. She's strange. She won't give us her name." At Pete's, I asked Lucy if she had ever encountered this woman. She had not, but the no-name policy piqued her curiosity, which she considered unfair. "Sure, she wants to know all the dirt but doesn't want to give anything," She said. More than six months passed until she finally revealed her name to Gladys, Carmen, and Lucy after months of sitting together at McDonald's.

In some situations, people used their status as old people with failing memories to explain why they or others did not know a person's name. Eugene recounted 
how he asked Joan, a woman in her early 70s, if she had seen Gladys at the senior center. He told her that she had some health problems that might interfere with her ability to care for herself. Unlike most research participants, both women regularly attended the center. "And she said, 'Gladys who?' Can you believe that? She doesn't even know her name," he said, raising his eyebrows. "Just a few weeks ago, she told me she [Gladys] was her secretary." He said that after Joan figured out she knew Gladys, she promised to inform the staff that Gladys might need help. Eugene repeated this anecdote throughout the evening. Lucy attributed Joan's ignorance to forgetfulness. "See, this is what you get when you deal with seniors. No one remembers anything. Mamma Mia! We're all falling apart." Perhaps this oversight resulted from forgetfulness, but the name issue may run deeper than a "senior moment." Not knowing Gladys's name freed Joan from a deeper obligation to help, though she agreed to alert the senior-center staff. Friends who know each other's names and histories demand more in terms of emotional obligation and practical assistance, such as serving as someone's emergency contact.

Although people used forgetfulness to explain losing track of people's names, such "memory lapses" did not impair participants' ability to remember nicknames. Participants used nicknames frequently and often exclusively. Years after Martin's death, I mentioned him to Eddie, who had known him for decades, but he did not know to whom I referred. After several attempts, he finally exclaimed in recognition, "Oh, little Marty!" Although participants could have used proper names, their range of nicknames for each other hinted not only at group standing (see Fine 1979) but a maneuver to maintain distance. Whether nicknames indicated affection ("little Marty"), admiration ("the lion"), or derision ("turkey neck"), they helped participants limit intimacy that may have forced them to transform elastic ties into strong ties. For instance, Eugene spent many years referring to a man who tried to befriend him by his nickname, "the photographer." But in recent years, he also invoked his proper name, T. J., in moments when he acknowledged his finer points and described how he had helped him, betraying some warmer feelings: "T. $\mathrm{J}$. is quite a pain, but he is always checking to see how I am, leaving books for me in the lobby, et cetera. You wouldn't know it, but he's really quite brilliant, reads a lot. He was a first-class photographer for the Daily News. With him, you can't get a word in edgewise, so he is quite a bore. But he has a good heart."

The majority of La Marjolaine's older customers lived alone, like Eugene, who illustrates how this place helped potentially vulnerable people avoid isolation and provided support to those without family nearby. But for him, this support did not translate into feelings of friendship or generate a roster of confidants. When Eugene's hip pain grew so severe that he could barely limp to the bakery, the company he found there provided practical assistance when he underwent major surgery at 84 years old and faced a grueling recovery while dealing with a string of setbacks. This setting also allowed him to draw on a reserve of goodwill he had built among regulars. He received at least 20 visitors in the hospital, who brought him food, newspapers, cards, balloons, and their well wishes. His first night back, though thinner and paler, he returned to the bakery. But his bathroom shower and sink had not been repaired, forcing him to lug pots of water from the kitchen for sponge baths. The situation lasted 45 days, and as one of a handful of rent-stabilized 
tenants in his building, he concluded, "They want to kill me. They want me out." Bakery people offered advice, lawyer referrals, calls to the building department, and perhaps most importantly, a willingness to listen.

As this vignette illustrates, this site served as a source of social resources. Yet when interviewed, Eugene did not identify close friends or people with whom he could discuss important things from the bakery. To my surprise, he did not even mention Sylvia. But whether he identified confidants, he benefited from his frequent associations. Although he readily called the bakery crowd friends, when asked later in the interview about his friends, "from pretty good friends to close friends," he responded: "I only have two close friends, Maggie and her mother. Well, Maggie and I have known each other 20 years or more. We used to sing together in a group. We would go to hospitals and nursing homes to give a performance. And we have mutual friends." At the time of interview, he estimated seeing Maggie once per month, but years later, he saw her far less frequently. Three years after the completion of fieldwork, Eugene admitted he had lost all contact with his friend and said, "I don't know if she's alive anymore."

When I asked Eugene the important-matters question, he did not mention Maggie, though he might have assumed he included her because he already discussed this close friendship. I asked: "From time to time, most people discuss things that are important to them with others. For example, these may include good or bad things that happen to you, problems you are having, or important concerns you may have. Looking back over the last 12 months, who are the people with whom you most often discussed things that were important to you?" He answered: "They [his family] ask me what's going on, and I keep them abreast. And of course, my agent. That's about it. Everyone else is dead or moved away."

Eugene is not the only person who hesitated to identify those with whom he socializes most as good friends or people with whom he could discuss personal things. During an interview with another bakery regular, an African American woman in her early 60s, I asked if she considered anyone there a friend. Like Eugene, Diane had a chatty disposition and interacted daily with other frequent patrons for 3.5 years prior, since moving back to the neighborhood after two decades in South Carolina, where her husband passed away. After hesitation, she applied the friend label, but the long pause beforehand suggested she only had under pressure to categorize people and acknowledge their closeness despite her uncertainty. Yet, she would not use the language of friendship to describe these associations. When asked if she made close friends at the site, she answered "no" without hesitation. I asked if she had close friends. The woman she named had been a friend for decades. Although she did not see her nearly as often as the bakery people, only about three times per month, she fit into a definable friendship. These cases represent a larger pattern among participants who define friends as relationships spanning several decades, more often sustained through sporadic in-person contact and phone calls rather than face-to-face interaction (see Wellman 1979).

Gossiping and badmouthing also created distance yet did not prevent people from spending time with those they disparaged. For example, Phyllis criticized Dottie, an 83-year-old retired telephone company worker, about her weight, poor diet, and lack of exercise. These critiques increased as Dottie had trouble leaving 
the house because of growing physical limitations, after her hospitalization for a heart attack and transfer to a nursing home, and after her death. Phyllis also denigrated McDonald's as "The Dementia Club" and discouraged Lucy from going there, saying "You are what you are by who you hang out with." Yet when Dottie entered the hospital, Phyllis visited her regularly and updated Dottie's condition for others in the neighborhood who could not or would not visit. Though she curtailed her time in McDonald's, she continued to go and maintained a relationship with Dottie until her death. Lucy, too, spoke of wanting to avoid "broken-down" and "dysfunctional" people, whom she lamented finding everywhere (her building, the supermarket, the doctor's office). Like Phyllis, she identified McDonald's as a bastion of "falling-apart women." But these protestations had not kept Lucy away.

When the obligations of strong ties overwhelmed, people also temporarily pulled back. For example, Carmen confessed not wanting the responsibility of walking Ethel, 90 years old, home every evening. Theresa had walked Ethel home because she suffered from vertigo and had no one to accompany her. After Theresa went to live with her brother in Hoboken because of worsening dementia, Carmen avoided McDonald's for weeks. She told me she felt so much pressure to take Ethel home that she stopped coming. Days later, Lucy revealed similar pressure and declared, "I didn't want that job."

\section{The Demands of Acknowledged Friendships}

During crisis, the obligations and stresses of declared friendships surfaced. In these situations, many either rallied around the person in need or withdrew. Some chose a middle ground, steering clear of deep involvement but helping more modestly. Even those who gave significant help incorporated distance into their accounts of their involvement. Dottie's case illustrates why people may avoid acknowledging more friends and is representative of the pushes and pulls research participants faced.

A lifelong neighborhood resident, Dottie seemed to be friends with everyone. Eugene joked that she knew everyone within a 10-block radius. Her humor and sharp tongue, combined with the time she spent in the neighborhood, enabled Dottie to add new acquaintances to her reserve of long-term ties. After the bakery closed, Dottie joined the women who regrouped at McDonald's. But deteriorating health made the additional three-block walk difficult. Though she went to the bakery nearly every morning and evening, severe leg pain reduced her McDonald's trips to once per week until weeks passed without anyone seeing Dottie. She spoke about being upset about the bakery closing and the effect on her life: "We had it good. But now it's gone. That broke a lot of friendships. Everyone goes their separate ways. This one there, that one here. It's not the same."

At McDonald's, Dottie met with a group that averaged six women, and yet she felt both left out and the center of unwanted attention. Since the closing, she noted falling off the radar of other bakery regulars. "Eddie used to call. He'd ask, 'How's your brother? How you doin', Dottie?' I guess no more, 'How you doing, Dottie?' But that's okay. I'm a loner. I'm by myself. Everybody's got their own life." She mentioned not speaking with Sylvia since the closing. "I don't hear from Sylvia 
no more. She don't call. And now she's hooked up with Phyllis and Judy. I don't blame her. They like to go places where they walk a lot." But the attention she received because of her mobility issues made her uncomfortable. "They know I'm coming, and they all show up because I don't come out a lot. The girls all want to help, but I feel bad. Lucy said she wanted to walk me home, but she just got there. It's not fair," she explained. Walking Dottie home was no small favor, as I discovered one afternoon. The three-block walk took 40 minutes, with many rest stops along the way. After a few plodding steps, Dottie breathed hard and sweat dripped down her face. A block later, she mentioned needing to lean against a car, another break built into her routine. As we approached a car, the vehicle moved, so we walked past several empty spaces until we found another. Dottie said that if she could not manage the walk home, "I take a taxi."

Six months later, Dottie suffered a heart attack. Her connection with others saved her life that day. When she did not show up for a birthday party in her building's community room, a neighbor checked on her and found Dottie on the floor. She spent six weeks in the hospital, followed by two more in a nursing home before she died at 83 years old. Her rapid deterioration tested the strength of people's ties. She received many regular visitors, but not everyone went to see Dottie. Some claimed that their own health problems prevented them. "My doctor said I'm not supposed to go into hospitals," Sylvia mentioned whenever Dottie's visitors updated the group at Pete's. Others provided no explanation. Though Phyllis had distanced herself from the McDonald's group, she visited Dottie regularly. Lucy proved one of Dottie's most reliable visitors but accumulated stresses on her almost daily visits, such as getting home late, skipping dinner, fatigue, and emotional drain. Nevertheless, she admitted, "It's hard to leave. I have a girlfriend who told me, 'You're not family; I'm going to time how long you stay there.' She's right." Dottie's only child compelled her to visit more and stay longer. "I try and be there for Linda, but my day is right around the corner, and who's gonna be there for me?" she said. Lucy said that she was glad when I visited because she could leave earlier. She hypothesized about others' absence: "You know what, we're old people, and we don't want to see it because we're getting old. It's scary. They don't want to see what's happening to Dottie. They told me so. They said, 'We're only gonna stay an hour.' Phyllis told me this, and Carmen only comes once in a while." Lucy explained how the group interpreted her frequent visits, saying, "You know, I'm considered Dottie's best friend." She did not say whether she or Dottie agreed.

I also found these visits emotionally and physically draining. Dottie could barely lift her arm to feed herself and could no longer walk, so visits often involved tasks such as filling water cups, cutting food into pieces, and relaying Dottie's needs to nurses and doctors. Her eyes remained unfocused, the lids puffy and dark, and without dentures, her words came out garbled. Black, purple, and yellow bruises riddled her arms from IVs inserted daily for weeks. Though Dottie retained a gallows humor until the end, she became disoriented and less accepting that she might never go home. She begged for company and feared dying at night when fewer staff attended to patients. Dottie's tears and pleas to stay "just a little longer" made it difficult to leave and recover from these visits. 
As Dottie faced a permanent move to a nursing home, people debated where she should go. Dottie's neighborhood ties thought she should move near her daughter to make visits easier. "Linda wanted to put Dottie in a place closer to where she lives, out in Queens, but Dottie said 'no,"' Lucy reported. "She wants to be close to her friends," she added. "Friends, what friends? Three friends," Judy chimed in. "That's right," Phyllis murmured in agreement. But Linda presented things differently and suggested that she, too, wanted Dottie to be "somewhere where her friends can visit her."

The decision to frame this issue around others' interests revealed perhaps genuine concern but also a strategy to ease the responsibility of visiting Dottie for everyone. If Dottie moved to Queens, her neighborhood ties would have had difficulty traveling and a valid reason not to visit her. Linda's concern for her mother's friends underscored her interest in not moving Dottie close to her, as her visits would have conceivably increased in number and duration. Dottie already complained that Linda did not visit enough, though she never missed more than a day. Prior to Dottie's illness, Linda saw her mother once or twice per month at most.

\section{Discussion}

\section{Motivations for Downplaying Ties}

Why do study participants downplay their ties? Three possibilities emerge: avoiding relationship risks and responsibilities (and thus protecting the self), the difficulty of replacing lost ties, and identification. These motivations illuminate the benefits of elastic ties for people who seek connection but who also, for good reason, inject distance into their interactions.

Three-quarters of my participants discussed the challenges of remaining independent, and one-third noted how the stress of dealing with others' problems interfered with caring for themselves. For example, Lucy's and Carmen's avoidance of a woman with whom they had interacted daily for the 18 months shows the burdens involved with closer relationships. If Carmen and Lucy recognized deeper bonds with Ethel and identified her as a friend rather than simply another person sitting with them, they might have felt obligated to rearrange their routines to assist or felt guilty for not helping more. Lucy has said often, in reference to the daily hassles of life, "I used to be a fighter, but I don't have the energy for that anymore." The majority of my research participants offered similar statements about a growing lack of energy compared with when they were younger. Their accounts of feeling overburdened support prior findings about older adults' sense of precariousness and needing to slow down, pace activities, and prioritize activities of daily living, such as cleaning and caring for the self (Abramson 2015; Portacolone 2013; Victor et al. 2009). These public statements may also deter others from seeking their support in the future.

The theme of lost ties arose almost daily with participants. Early in Eugene's interview, he reflected: "I have friends, not many... most are dead or moved away. No, seriously, most are dead or moved away. I can just think of so many that 
have passed. And of course, my parents are dead." During the Thanksgiving and Christmas holiday season, while surrounded by people he had known and interacted with for years who appeared to be friends, Eugene remarked similarly when asked about his holiday plans. He would spend those days alone working because "all my friends are dead." These statements reveal the difficulty older people have replacing lost ties, which echo earlier findings (Cornwell et al. 2008) and may explain why important-matters or close-friends questions elicit kin ties or long-term friendships but not the relationships I observed in public places. Such statements recall something the priest at Dottie's funeral said: "Death is not the end of human relationship." In some ways, these people acted as substitutes for lost ties. But my participants thought of relationships developed later in life differently and appeared to have difficulty absorbing them into their pool of long-term associations. Upon death, interaction ended, but people kept the dead alive through reminiscence and memory. In Sylvia's case, she built relationships with people connected to those she had lost (e.g., befriending her husband's younger college classmates and the children of deceased friends). Like Eugene, she counted these enduring relationships as "truer" friendships. Of the people she had interacted with daily in the neighborhood for years, she said: "God bless these women, but they're not my world."

Disavowing ties also relates to identification-specifically, avoiding the stigma of aging. Attachment to longstanding relationships reflects a desire to view oneself at younger ages and in corresponding roles (e.g., wife, mother, sister, etc.), which dwindle with each lost tie. Embracing new ties requires a higher degree of reinvention and reimagining than my participants seemed willing or able to undertake. Shifting networks over the life course can mean that, with retirement and the death of relatives, the workplace and family as sources of strong ties diminish and the neighborhood rises in importance (Fischer 1982; Hochschild 1973). This shift may account for some downplaying of ties because people do not fully recognize (or want to recognize) that their "friends" and "associates" have changed along with daily routines. Old people do not often think of themselves as old (Taylor et al. 2009; Victor et al. 2009), and distancing from other old people (e.g., Phyllis's reference to "The Dementia Club") can help avoid the stigma of age (Cruikshank 2009). Downplaying ties with other elders (or selectiveness with those identified as friends) helps the old protect their self-image, albeit through internalized ageism. When I asked Eugene why he did not go to senior centers, he answered: "I hate old people."

In the context of these motivations for creating distance and downplaying intimacy, elastic ties serve as an important means of staying connected for people who could become isolated under other circumstances. When the pressures of dealing with others overwhelm, elastic ties allow retreat without confrontation. When Sylvia had had enough of Lucy's venting, she announced she would "take a vacation" from Pete's for a few days. "Yeah, it's nice to have a change of scenery," Lucy said, unaware that she motivated this break. Three days later, Sylvia returned. When comparing neighborhood women with her lifelong friends, she claimed, "I never met such a cruel group." Phyllis revealed she, too, needed escape from Lucy and Sylvia six weeks after she disappeared from Pete's. She disliked Lucy's 
"negativity" and celebrity gossip and Sylvia's jealousy of her closeness with Eugene. "I've been through that before. There's one man around, and all the women get jealous," she said. Phyllis described avoiding Pete's as part of a larger, positive development in her life. She had cut other ties and quit playing bingo. "I'm going to museums now, learning things, doing things on my own. ... It's a new life for me," she said. Her previous break from McDonald's and reentry with Dottie's illness shows the forgiving nature of elastic ties. After we ate dinner across the street from Pete's, she proposed going there "for a few minutes to say hello," suggesting that as much as elastic ties offer easy exit, these attachments remain difficult to abandon. Three years after the completion of fieldwork, I ran into Phyllis on her way to McDonald's. Despite her latest complaints about her frailer age peers, she still maintained some continuing, if sporadic, connection to the older people she had met at neighborhood eateries. Given these motivations, we must approach people's accounts of their relationships with skepticism. Understanding how people act as confidants towards each other in different situations underscores the slippery nature of this category and the limitations of understanding how people meet their needs for human connection solely though respondents' accounts.

\section{Conceptualizing Elastic Ties}

Are elastic ties merely a species of weak ties? I argue that we need to conceive of them as a separate form of tie. Elastic ties do not simply provide passing acquaintanceship, information, or bridges to other groups and networks, as Granovetter (1973) has conceptualized weak ties. Perhaps they originate here but rather than becoming traditional strong ties, they continue to exist outside weak and strong. Instead, elastic ties possess elements of both types, which combine to create a new category that offers participants a third way to insert distance but retain intimacy. As Sylvia remarked about her relationship with Eugene, "I know him, but I don't." Comparing elastic ties with other relations that merge closeness and distance may help clarify the theoretical significance of these relationships for the study of neighborhoods, networks, and social support for elders and other vulnerable individuals.

Prior network research has developed not only a middle-class model for social ties (Desmond 2012) but one anchored in experiences pressing for younger people, such as career advancement and workplace connections. Other work has found "business-like but intimate" relationships emerge in structured community service (Wireman 1984:10). Though these "intimate secondary relationships," as Wireman calls them, meld distance and intimacy, their middle-class participants typically engage in additional activities and avoid deeper involvement with others. As Lofland (1998) points out, those relationships tend to have a positive emotional tinge due to their easy withdrawal and lack of attachment. Despite their stated wishes not to, my research participants became deeply involved with each other. Difficulty disposing of these ties make them different from the compartmental tie theorized by Small (2009), maintained by organizations and thus perhaps easier to drop.

Although many participants belonged to multiple networks, their constraints in old age converged to render the neighborhood not as simply one of several, equal 
bases of partial commitment in a "community of limited liability" (Greer 1962) but a site of deepening investment and interaction. Local geography rose in importance with physical limitations, losses of family and friends, and unstructured time in retirement rather than homeownership and child-rearing as Greer (1962) discusses (see also Guest et al. 2006; Wellman and Leighton 1979). Repeated interactions at different neighborhood places also heightened obligation, offering insight into the constraints that may compel people to retain network members whom they find demanding and difficult (Offer and Fischer 2017) and how people use distancing as a tie management strategy.

Ties remained elastic for my study participants because of their precarious position later in life, which compelled them to work within growing constraints to meet their needs for connection and support. Contrary to Rainie and Wellman's (2012:125) claim that "people have more freedom to tailor their interactions. They have increased opportunities about where-and with whom-to connect," my participants faced less choice in their interactions. Their gathering spots dwindled due to a changing retail environment that closed establishments and posed economic barriers to accessing their replacements. Many became "stuck in place," lacking the social and physical resources to comfortably age in place (Scharlach and Lehning 2016; Torres-Gil and Hofland 2012). As physical issues arose and retirement ended old routines, people formed ties with people they never considered important before, such as neighbors. For example, Sylvia forged relationships with younger neighbors following her husband's death. A middle-aged gay couple next door helped with small but daunting tasks, such as programming her television remote control. Sylvia had family but relied on these extrafamilial relationships to avoid overstressing kin networks. Fashioning ties with neighbors also supported her independence and helped her rebuff offers from well-meaning relatives to move in with them.

The elasticity of these ties also mirrors the unstructured time that my participants confronted at this point. The majority avoided formal organizations or institutions, such as senior centers and church (see Weil 2014 for more discussion of senior centers). For the few who attended, these activities supplemented rather than structured their daily routines. The public places where my participants formed elastic ties helped fill gaps of time that caused unease for some (Victor et al. 2009) but with fluidity that befitted their freedom from rigid work schedules. Moreover, the spaces that facilitated the development of these ties provided a reason to leave the house besides daily errands and medical appointments. The majority of my participants expressed the importance of going outside each day. As Sylvia summed up, no matter how badly she felt, "You've got to get out of bed and put your lipstick on."

The emergence of elastic ties also corresponds to a changing relationship to the neighborhood upon retirement and the end of child-rearing responsibilities. I asked Phyllis once if she remembered the storefronts along an avenue one block past her apartment. "I have no idea. I never went there," she said. Despite living in the neighborhood for a half-century, working multiple jobs and raising two sons created a routine that left little time to explore the neighborhood. She had no practical reason to familiarize herself with this area until after retirement. Others became 
regulars at neighborhood establishments upon retirement and, for women who did not engage in paid labor, after their partners died and children had moved away.

The desire for closeness and distance in social relationships is not exclusive to older adults or any group of people. As we move through our lives, we encounter situations that blend intimacy and detachment. For example, when I accompanied Angelica to a surgical breast cancer consult at a large public hospital, a woman in the waiting room disclosed her HIV status to me. She had told few in her social circle and said, "I don't care if you know because I'm never going to see you again." A similar type of deep and spontaneous revelation can happen in a bar or any context where alcohol and other substances loosen lips and inhibitions. Encounters that blend confiding with the fleeting exchange of minimal identifiers carry less risk given the limited time frame and anonymity.

Other contexts in which people betray closeness but maintain boundaries over a longer stretch of time include the workplace or organizations such as a day care center (Small 2009). We even have a special word, collegiality, for the camaraderie and cooperation between coworkers (Merriam-Webster 2017). Support groups, such as Alcoholics Anonymous, mirror some of the conditions and setting characteristics of elastic ties insofar as participants create spaces where communication about sensitive topics occurs on the condition of confidentiality. People share painful histories and struggles with addiction, often enlisting individual sponsors who support them outside the meeting space, but adhere to rules, such as avoiding last names, that protect privacy and maintain distance. Unlike elastic ties, these examples of closeness and distance have firmer boundaries, occur in more organized spaces defined by purpose or activity, or involve shorter time commitments.

Older adults and other vulnerable people without work and family to impose structured support have higher needs, vulnerability, and disincentives to get too close or else incur the burden and expense of strong ties (for an excellent discussion about why people may avoid confiding in close relations, see Small 2017). Participants in the closeness-distance examples I have noted tend to have greater options for tie formation. Despite the limitations of my small sample, in light of the conditions I have identified for elastic ties, future research might expect to find similar ties among vulnerable people constrained in urban spaces, with high need, low resources, and weak support, such as those struggling with a serious physical or mental illness, unemployment, or living on the street. Stuart's (2016) finding of how Los Angeles Skid Row residents constricted their relationships with each other because of the threat of unwanted police contact offers a clue to other contexts in which people may rely upon each other while also having to maintain distance.

Shifting from the perspective of tie formation as a deliberate process to focusing on contexts that offer people opportunity to create ties (Offer and Fischer 2017; Small 2017) would help increase researchers' chances of capturing the elastic relationships I have identified. This study offers promising avenues for future research on the personal networks of older adults and other vulnerable individuals. Integrating a deeper understanding of barriers to tie formation for vulnerable people and designing social-network items to collect detailed data about respondents' time and place usage and daily routines would increase the likelihood that researchers 
discover these less easily categorized, yet vital, relationships formed in response to multiple needs and constraints.

\section{Conclusion}

This study has presented an alternative conceptualization of social ties that defy categorization as either weak or strong-the predominate classification in most social-network research to date. Elastic ties more accurately convey the ambiguous relationships people forge in face-to-face interaction with others who fall outside the traditional parameters of close friends and family. They challenge conventional wisdom that weak ties provide information and strong ties provide support. Elastic ties incorporate elements of both, as people with reasons to resist the commitments of deeper friendship but want to avoid isolation find a third way to feel connected but not stifled. These relationships rise in salience in late life as older adults work within growing constraints associated with retirement, physical limitations, and the loss of spouses, partners, and friends to meet their needs for connection and support while preserving autonomy.

This strategic fashioning of ties recalls Simmel's ([1908] 1971) writings on the stranger and Jacobs's (1961) celebration of the supportive but delimited social bonds that vibrant urban public spaces foster. Despite their familiarity and regular interaction with others with whom they shared elastic ties, participants strived to occupy something of a permanent stranger status and longed for the freedom that came with distance. Elastic ties' mingling of distance and intimacy explains how a person who may claim to have no friends could still avoid loneliness or social isolation. My findings suggest that researchers may miss many nuances of social relationships if they neglect the fleeting and spontaneous interactions that form the backbone of elastic ties. At best, survey measures of social networks and isolation such as the important-matters question provide a partial picture of a respondent's social ties. At worst, they may distort social connection and the myriad ways people derive social support and organize everyday life. In situ observations of people's relationships provide a check against participant accounts and the static character of large surveys, which can only capture respondents' decontextualized claims about their networks at a single moment, thereby glossing the complexity of ties formed in daily interaction.

\section{Notes}

1 To protect the confidentiality of my research participants, I have changed the names of most sites and people. In accordance with my approval from the institutional review board for research with human subjects to conduct participant observations and interviews, I explained to participants that I would take every measure to protect their confidentiality, such as providing pseudonyms and omitting some identifying details if necessary, though I could not guarantee anonymity. Participants have not read or given comments on this manuscript.

2 A co-op is a residence where a buyer purchases a share in the corporation that owns the building where he or she lives and has the right to occupy a specified unit and a 
vote in the corporation. Low-equity co-ops limit the resale of shares, helping to preserve affordable housing (National Association of Housing Cooperatives 2012).

3 I use quotes when I wrote down verbatim in my notebook what people said as they spoke or shortly afterwards and when I transcribed dialogue from tape recordings made in the field or during an interview. Speech in quotes should be taken only as a close approximation.

\section{References}

Abramson, Corey M. 2015. The End Game: How Inequality Shapes Our Final Years. Cambridge, MA: Harvard University Press. https : //doi .org/10.4159/9780674286801.

Anderson, Elijah. 2004. "The Cosmopolitan Canopy." The Annals of the American Academy of Political and Social Science 595:14-31. https://doi .org/10.1177/0002716204266833.

Bailey, Stephanie, and Peter Marsden. 1999. "Interpretation and Interview Context: Examining the General Social Survey Name Generator Using Cognitive Methods." Social Networks 21:287-309. https://doi.org/10.1016/S0378-8733(99)00013-1.

Bearman, Peter, and Paolo Parigi. 2004. "Cloning Headless Frogs and Other Important Matters: Conversation Topics and Network Structure." Social Forces 83:535-57. https : //doi.org/10.1353/sof.2005.0001.

Bellah, Robert, Richard Madsen, William M. Sullivan, Ann Swidler, and Steven M. Tipton. [1985] 1996. Habits of the Heart: Individualism and Commitment in American Life. Berkeley, CA: University of California Press.

Ben Noon, Rinat, and Liat Ayalon. 2018. “Older Adults in Open Public Spaces: Age and Gender Segregation." The Gerontologist 58:149-58. https://doi.org/10.1093/geront/ gnx047.

Brown-Saracino, Japonica. 2011. "From the Lesbian Ghetto to the Ambient Community: The Perceived Costs and Benefits of Integration for Community." Social Problems 58:361-88. https://doi.org/10.1525/sp.2011.58.3.361.

Cagney, Kathleen A., Christopher R. Browning, Aubrey L. Jackson, and Brian Stoller. 2013. "Networks, Neighborhoods, and Institutions: An Integrated 'Activity Space' Approach for Research on Aging." Pp. 150-74 in New Directions on the Sociology of Aging, edited by L. J. Waite and T. J. Plewes. Washington, DC: National Academies Press. Retrieved October 8, 2017 (https://www.ncbi.nlm.nih.gov/books/NBK184369/).

Carstensen, Laura L. 1992. "Social and Emotional Patterns in Adulthood: Support for Socioemotional Selectivity Theory." Psychology and Aging 7:331-8. https ://doi .org/10. 1037/0882-7974.7.3.331.

City of New York. 2016. "Senior Citizen Rent Increase Exemption (SCRIE)." City of New York. Retrieved September 26, 2017 (http://www1.nyc.gov/nyc-resources/service/ 2424/senior-citizen-rent-increase-exemption-scrie).

Cornwell, Benjamin, Edward O. Laumann, and Philip L. Schumm. 2008. “The Social Connectedness of Older Adults: A National Profile." American Sociological Review 73:185203. https://doi.org/10.1177/000312240807300201.

Cruikshank, Margaret. 2009. Learning to Be Old: Gender, Culture, E Aging. New York, NY: Rowman \& Littlefield Publishers, Inc.

Desmond, Matthew. 2012. "Disposable Ties and the Urban Poor." American Journal of Sociology 117:1295-335. https://doi .org/10.1086/663574. 
Duneier, Mitchell. 1992. Slim's Table: Race, Respectability, and Masculinity. Chicago, IL: University of Chicago Press.

Durkheim, Emile. [1897] 1951. Suicide: A Study in Sociology. Translated by J. A. Spaulding and G. Simpson. New York, NY: Free Press.

Feld, Scott L. 1981. "The Focused Organization of Social Ties." American Journal of Sociology 86:1015-35. https://doi.org/10.1086/227352. https://doi .org/10.1086/227352.

Fine, Gary Alan. 1979. "Small Groups and Culture Creation: The Idioculture of Little League Baseball Teams." American Sociological Review 44:733-45. https://doi.org/10.2307/ 2094525.

Fischer, Claude S. 1982. To Dwell among Friends: Personal Networks in Town and City. Chicago, IL: University of Chicago Press.

Fischer, Claude S. 2009. "The 2004 GSS Finding of Shrunken Social Networks: An Artifact?" American Sociological Review 74:657-69. https://doi.org/10.1177/ 000312240907400408.

Furman, Frida Kerner. 1997. Facing the Mirror: Older Women and Beauty Shop Culture. New York, NY: Routledge.

Gieryn, Thomas F. 2000. "A Space for Place in Sociology." Annual Review of Sociology 26:46396. https://doi.org/10.1146/annurev.soc.26.1.463.

Goffman, Alice. 2009. “On the Run: Men Wanted in a Philadelphia Ghetto." American Sociological Review 74:339-57. https://doi .org/10.1177/000312240907400301.

Granovetter, Mark. 1973. “The Strength of Weak Ties.” American Journal of Sociology 78:136080. https://doi.org/10.1086/225469.

Greer, Scott. 1962. The Emerging City: Myth and Reality. New York, NY: Free Press.

Guest, Avery M., Jane K. Cover, Ross L. Matsueda, and Charis E. Kubrin. 2006. “Neighborhood Context and Neighboring Ties." City \& Community 5:363-85. https : //doi . org/10 . $1111 / j .1540-6040.2006 .00189 . x$.

Gusmano, Michael K., and Victor G. Rodwin. 2006. "The Elderly and Social Isolation: Testimony to Committee on Aging, NYC Council, February 13, 2006." Retrieved March 21, 2010 (https://pdfs.semanticscholar.org/5cd4/ edd23128103fdd58d53199049cc4a7f7ad45.pdf).

Hochschild, Arlie Russell. 1973. The Unexpected Community: Portrait of an Old Age Subculture. Englewood Cliffs, NJ: Prentice-Hall.

Hooyman, Nancy R., and Asuman H. Kiyak. 2008. Social Gerontology: A Multidisciplinary Perspective. 8th ed. New York, NY: Pearson.

Interboro Partners. 2010. "NORCs in NYC." Architectural League of New York. Retrieved March 17, 2010 (http: //urbanomnibus .net/2010/03/norcs-in-nyc/).

Jacobs, Jane. 1961. The Death and Life of Great American Cities. New York, NY: Modern Library.

Jerolmack, Colin, and Shamus Khan. 2014. "Talk is Cheap: Ethnography and the Attitudinal Fallacy." Sociological Research Methods 43:178-209. https://doi .org/10.1177/ 0049124114523396.

Katz, Jack. 1997. “Ethnography's Warrants.” Sociological Methods and Research 25:391-423. https://doi.org/10.1177/0049124197025004002.

Khan, Shamus, and Colin Jerolmack. 2013. "Saying Meritocracy and Doing Privilege." The Sociological Quarterly 54:9-19. https://doi.org/10.1111/tsq.12008.

Klinenberg, Eric. 2002. Heat Wave: A Social Autopsy of Disaster in Chicago. Chicago, IL: University of Chicago of Press. https://doi.org/10.7208/chicago/9780226026718. 001.0001. 
Klinenberg, Eric. 2012. Going Solo: The Extraordinary Rise and Surprising Appeal of Living Alone. New York, NY: Penguin Press.

Kugelmass, Jack. [1986] 1996. Miracle of Intervale Avenue: The Story of a Jewish Congregation in the South Bronx. New York, NY: Columbia University Press.

LaPiere, Richard. 1934. "Attitudes vs. Actions." Social Forces 13:230-7. https://doi .org/10. $2307 / 2570339$.

Liebow, Elliot. 1967. Tally's Corner: A Study of Negro Streetcorner Men. Boston, MA: Little, Brown and Company.

Loe, Meika. 2011. Aging Our Way: Lessons for Living from 85 and Beyond. New York, NY: Oxford University Press.

Lofland, Lyn H. 1973. A World of Strangers: Order and Action in Urban Public Space. New York, NY: Basic Books.

Lofland, Lyn H. 1998. The Public Realm: Exploring the City's Quintessential Social Territory. New York, NY: Aldine de Gruyter.

Longitudinal Aging Study Amsterdam. 2017. Longitudinal Aging Study Amsterdam. Vrije Universiteit Amsterdam. Retrieved July 14, 2017 (http: //www.lasa-vu.nl/index.htm).

Marsden, Peter V. 1987. “Core Discussion Networks of Americans." American Sociological Review 52:122-31. https://doi .org/10.2307/2095397.

Marsden, Peter V. 1993. "The Reliability of Network Density and Composition Measures." Social Networks: 15:399-421. https://doi .org/10.1016/0378-8733(93)90014-C.

McPherson, Miller, Lynn Smith-Lovin, and James M. Cook. 2001. “Birds of a Feather: Homophily in Social Networks." Annual Review of Sociology 27:415-44. https://doi . org/10.1146/annurev.soc.27.1.415.

McPherson, Miller, Lynn Smith-Lovin, and Matthew E. Brashears. 2006. "Social Isolation in America: Changes in Core Discussion Networks over Two Decades." American Sociological Review 71:353-75. https://doi.org/10.1177/000312240607100301.

Merriam-Webster. 2017. "Collegiality." Merriam-Webster. Retrieved October 7, 2017 (https : //www . merriam-webster.com/dictionary/collegiality).

Milgram, Stanley. 1977. "The Familiar Stranger: An Aspect of Urban Anonymity." The Individual in a Social World: Essays and Experiments. New York, NY: Longman Higher Education.

Morgan, David. 2009. Acquaintances: The Space between Intimates and Strangers. New York, NY: Open University Press.

Morrill, Calvin, and David A. Snow. 2005. "The Study of Personal Relationships in Public Places." Pp 1-22 in Together Alone: Personal Relationships in Public Places, edited by C. Morrill, D. A. Snow, and C. White. Berkeley, CA: University of California Press.

Myerhoff, Barbara. 1978. Number Our Days. New York, NY: Simon \& Schuster.

National Association of Housing Cooperatives. 2012. "Buying into a Housing Cooperative." Retrieved August 13, 2012 (https://coophousing.org/resources/ owning-a-cooperative/buying-into-a-housing-cooperative/).

National Social Life, Health, and Aging Project. 2011. "National Social Life, Health, and Aging Project." NORC at the University of Chicago. Retrieved July 14, 2017 (http://www.norc.org/Research/Projects/Pages/ national-social-life-health-and-aging-project.aspx).

Niesz, Helga. 2007. Naturally Occurring Retirement Communities. Office of Legislative Research: Research Report. Hartford, CT: Connecticut General Assembly. Retrieved December 21, 2009 (http: //www. cga.ct.gov/2007/rpt/2007-R-0148.htm). 
Offer, Shira, and Claude Fischer. 2017. "Difficult People: Who Is Perceived to Be Demanding in Personal Networks and Why Are They There?" American Sociological Review 83:111-42. https://doi.org/10.1177/0003122417737951.

Oldenburg, Ray. [1989] 1999. The Great Good Place: Cafes, Coffee Shops, Bookstores, Bars, Hair Salons and Other Hangouts at the Heart of a Community. New York, NY: Marlowe \& Company.

Paik, Anthony, and Kenneth Sanchagrin. 2013. "Social Isolation in America: An Artifact." American Sociological Review 78:339-60. https://doi .org/10.1177/0003122413482919.

Plickert, Gabriele, Rochelle R. Côté, and Barry Wellman. 2007. "It's Not Who You Know, It's How You Know Them: Who Exchanges What With Whom?" Social Networks 29:405-29. https://doi.org/10.1016/j. socnet.2007.01.007.

Portacolone, Elena. 2013. “The Notion of Precariousness among Older Adults Living Alone in the U.S." Journal of Aging Studies 27:166-74. https://doi.org/10.1016/j.jaging. 2013.01 .001$.

Putnam, Robert D. 2000. Bowling Alone: The Collapse and Revival of American Community. New York, NY: Simon \& Schuster.

Rainie, Lee, and Barry Wellman. 2012. Networked: The New Social Operating System. Cambridge, MA: The MIT Press. https://doi.org/10.7551/mitpress/8358.001.0001.

Sampson, Robert J. 2012. Great American City: Chicago and the Enduring Neighborhood Effect. Chicago, IL: University of Chicago Press. https://doi.org/10.7208/chicago/ 9780226733883.001 .0001$.

Scharlach, Andrew. E., and Amanda J. Lehning. 2016. Creating Aging-Friendly Communities. New York, NY: Oxford University Press.

Schnittker, Jason. 2007. "Look (Closely) at All the Lonely People: Age and the Social Psychology of Social Support." Journal of Aging and Health 19:659-82. https : //doi .org/ 10.1177/0898264307301178.

Simmel, Georg. [1908] 1971. "The Stranger." Pp. 143-9 in On Individuality and Social Forms, edited by D. N. Levine. Chicago, IL: University of Chicago Press.

Simmel, Georg. [1910] 1971. "Sociability." Pp. 127-40 in On Individuality and Social Forms, edited by D. N. Levine. Chicago, IL: University of Chicago Press.

Small, Mario Luis. 2009. Unanticipated Gains: Origins of Network Inequality in Everyday Life. New York, NY: Oxford University Press. https://doi.org/10.1093/acprof : oso/ 9780195384352.001 .0001$.

Small, Mario Luis. 2013. "Weak Ties and the Core Discussion Network: Why People Regularly Discuss Important Matters with Unimportant Alters." Social Networks 235:47083. https://doi.org/10.1016/j. socnet.2013.05.004.

Small, Mario Luis. 2017. Someone to Talk to. New York, NY: Oxford University Press. https://doi.org/10.1093/oso/9780190661427.001.0001.

Stuart, Forrest. 2016. "Becoming 'Copwise': Policing, Culture, and the Collateral Consequences of Street-Level Criminalization." Law E Society Review 50:279-313. https : //doi.org/10.1111/lasr.12201.

Stueve, C. Ann, and Kathleen Gerson. 1977. "Personal Relations across the Life-Cycle." Pp. 79-98 in Networks and Places: Social Relations in the Urban Setting, edited by C. S. Fischer, R. M. Jackson, C. A. Stueve, K. Gerson, L. McCallister Jones, and M. Baldassare. New York, NY: Free Press.

Suanet, Bianca, Theo G. van Tilburg, and Marjolein I. Broese van Groenou. 2013. “Nonkin in Older Adults' Personal Networks: More Important among Later Cohorts?" Journals 
of Gerontology, Series B: Psychological Sciences and Social Sciences, 68:633-43. https://doi . org/10.1093/geronb/gbt043.

Survey of Health, Ageing and Retirement in Europe. 2015. "SHARE - Survey of Health, Ageing, and Retirement in Europe." Survey of Health, Ageing and Retirement in Europe. Retrieved July 14, 2017 (http: //www . share-project.org).

Taylor, Paul, Rich Morin, Kim Parker, D’Vera Cohn, and Wendy Wang. 2009. "Growing Old in America: Expectations vs. Reality." Pew Research Center. Retrieved August 26, 2012 (https://www.pewresearch.org/wp-content/uploads/sites/3/2010/ 10/Getting-0ld-in-America.pdf).

Torres, Stacy. 2018. "Aging in Places." Pp. 151-63 in Critical Gerontology Comes of Age: Advances in Research and Theory for a New Century, edited by C. Wellin. New York, NY: Routledge, Taylor \& Francis. https://doi .org/10.4324/9781315209371-10.

Torres-Gil, Fernando, and Brian Hofland. 2012. "Vulnerable Populations." Pp. 221-31 in Independent for Life: Homes and Neighborhoods for an Aging America, edited by H. Cisneros, M. Dyer-Chamberlain, and J. Hickie. Austin, TX: University of Texas Press.

Townsend, Peter. 1957. The Family Life of Old People. London, United Kingdom: Routledge.

Victor, Christina, Sasha Scambler, and John Bond. 2009. The Social World of Older People. New York, NY: Open University Press.

Weil, Joyce. 2014. The New Neighborhood Senior Center: Redefining Social and Service Roles for the Baby Boom Generation. New Brunswick, NJ: Rutgers University Press.

Wellin, Christopher. 2010. "Growing Pains in the Sociology of Aging and the Life Course: A Review Essay on Recent Textbooks." Teaching Sociology 38:373-82. https ://doi . org/10. $1177 / 0092055 X 10380673$.

Wellman, Barry. 1979. “The Community Question: The Intimate Networks of East Yorkers." American Journal of Sociology 84:1201-31. https : //doi .org/10.1086/226906.

Wellman, Barry, and Barry Leighton. 1979. "Networks, Neighborhoods, and Communities: Approaches to the Study of the Community Question." Urban Affairs Quarterly 14:363-90. https://doi.org/10.1177/107808747901400305.

Wellman, Barry, and Milena Gulia. 1999. “The Network Basis of Social Support: A Network is More Than the Sum of Its Ties." Pp. 83-118 in Networks in the Global Village, edited by B. Wellman. Boulder, CO: Westview.

Wellman, Barry, and Scot Wortley. 1990. “Different Strokes from Different Folks: Community Ties and Social Support." American Journal of Sociology 96:558-88. https : //doi .org/10 . $1086 / 229572$.

Wireman, Peggy. 1984. Urban Neighborhoods, Networks, and Families. Lexington, MA: Lexington Books.

York Cornwell, Erin, and Linda J. Waite. 2009. "Social Disconnectedness, Perceived Isolation, and Health among Older Adults." Journal of Health and Social Behavior 50:31-48. https : //doi.org/10.1177/002214650905000103. 
Acknowledgments: I thank Kathleen Gerson, Colin Jerolmack, Lynne Haney, Steven Lukes, Dalton Conley, Ronald Breiger, Anthony Paik, and Claude Fischer for their guidance and feedback on earlier versions of this article. A special thanks to my study participants, who shared their lives with me for several years. Support for data collection and project write-up was funded in part by fellowships from New York University, the American Sociological Association Minority Fellowship Program (cosponsored by Sociologists for Women in Society), the Ford Foundation, and the UC President's Postdoctoral Fellowship Program. Publication is made possible in part by support from the UCSF Open Access Publishing Fund.

Stacy Torres: Department of Social and Behavioral Sciences, University of California, San Francisco. E-mail: stacy.torres@ucsf.edu. 